CASE 19. - A young girl died after having been paraplegic, and without having lost sensibility. The encephalon was in a normal condition, except that the corpora geniculata were of a grey colour. The spinal cord in all its length had a grey-rose colour column formed by the median posterior columns; the rest of this organ was healthy. (Cruveilhier, in Anat. Pathol., 32nd livraison, p. 21.)

It is quite certain that the loss of voluntary movement in this case cannot be attributed (at least only) to the alteration found in a small part of the cord; but we relate this fact (which Cruveilhier has pnblished without any detail) because it shows that there may be an alteration of the little median posterior columns with conservation of sensibility.

We might relate a great many other cases showing that alte. rations of the posterior columns do not produce anæsthesia, and are often, on the contrary, attended with hyperæsthesia. For the sake of brevity, we will merely point out a few circumstances connected with some of these cases, and give the references of the others. In a paper by Dr. Ludwig Tiurck (Beobachtungen über das Leitungsvermögen des Menschlichen Rückenmarkes, 1855), there is a case of old alteration of a part of the right side of the spinal cord extending between the origins of the fourth and sixth cervical nerves. In certain sections the alteration occupied a part of the lateral column and a part of the posterior column (see Fig. 16,al); and, in another section, (between the fifth and sixth cervical nerves), it occupied the whole of the right posterior columns. The altered parts were indurated, of a reddish-grey colour, and did not contain a trace of nerve-fibre. This alteration, therefore, had produced there just the same thing as a transversal section of the posterior column and of a part of the lateral column on the right side. Numerous and careful examinations have shown that the hands and fingers had no anæsthesia. In this case the anterior parts of the spinal cord were also altered in the cervical region, so that the transmission of sensitive impressions must have taken place through the central grey matter. The last examination of the state of sensibility unfortunately was made long before death; but the alteration found is one that occurs very slowly. The same remarks might apply to another case observed by the same pathologist. The two internal segments of the posterior columns (see Fig. 17,al) were altered (and without any trace of nerve-fibre) between the fifth and sixth cervical nerves, and sensibility to touch in the parts animated by these nerves persisted.
FIG. 16.

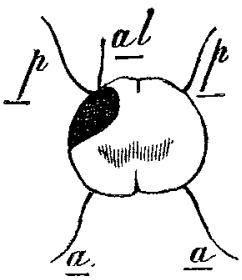

FIG- 17 .

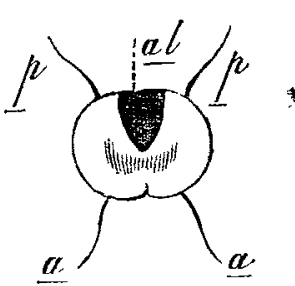

Figs. 16 and 17 represent sections of the spinal cord of man: $a l$ in both is an altered portion; $p, p$, the posterior roots; and $a, a$, the anterior roots.

Dr. R. B. Todd says, that in two cases which occurred in King's College Hospital, under his own care, the prominent symptom was impairment of the motor power, without injury to the sensitive; yet the seat of organic lesion in both was in the posterior columns of the cord. (Cyclopoedia of Anatomy and Physiol., vol. iii., p. 721, P.)

Serres speaks of a woman who had been paraplegic for two months, and had sensibility preserved in her lower limbs, although the posterior columns were alone altered, and in three places. (Anat. Comparée du Cerveau, vol. ii., p. 221.)

H. Nasse mentions a case, observed by Wittfeld, in which a tumour pressing upon the posterior columns in the lumbar region had produced a paralysis of movement, and not of sensibility. (Untersuchungen zur Physiol. und Pathol., vol. i., p. 226.)

Sandras says, without any more detail, that he has seen two cases of alteration of the posterior columns, in one of which sensibility was lost, and, in the other, voluntary movements. (Journal Général de Méd. \&c., p. 360.)

M. Nichet relates a very important case, of which we shall have to speak elsewhere, in which sensibility had persisted, although the spinal cord had been reduced to a thickness of two lines near the medulla oblongata, the grey matter, almost alone, seeming to exist. (Gaz. Méd. de Paris, 1835, p. 534.)

We might cite many other cases by Hutin, Pres, Velpeau, Bellingeri, Liberali, Colin, Bourdon, Ollivier, Caron, Hersent,
Fricault, Curveilhier, Guyon, Goupil, J. W. Ogle, \&c., in which sensibility has persisted, and, sometimes, has been much increased, although the posterior columns were the only, or principal seats of alteration.

I think that it is impossible, after such a mass of evidence, not to admit that if the posterior columns of the spinal cord convey sensitive impressions to the encephalon, their share in this function must be extremely slight.

In the next lecture, before speaking of the pathological facts which prove that the conductors of sensitive impressions de. cussate in the spinal cord, I will relate some facts concerning the transmission of these impressions through the grey matter, and discuss some important questions on the diagnostic value of anæsthesia and hyperæsthesia.

ON

\section{EXCISION OF THE TONGUE FOR CANCER.}

BY JAMES SYME, EsQ,

PROFESSOR OF CLINICAL SURGERT AT THE DNIVERSITY OF EDINBURGH.

There are few diseases more painful to suffer or more distressing to witness than cancer of the tongue. The concurrent testimony of all experienced practitioners is decidedly unfavour. able to operative interference by removal of the diseased part from its never affording permanent relief, and generally exciting, instead of retarding, the morbid progress, while all the means of palliation are extremely uncertain and inefficient. In circumstances so desperate any practicable measure affording a reasonable prospect of relief would certainly be warrantable; and under this impression I have lately tried the effect of extirpating the whole organ. As the disease frequently exists for a long while without extending beyond the tongue, and yet rapidly re-appears after the affected part has been cut freely away, there seemed reason to think that if the whole texture showing this disposition to morbid action were removed the patient might escape future trouble. Some reports had reached me of this having been done by cutting into the mouth under the chin, and then completing the operation by means of either a knife or the écraseur. But feeling assured that it was impossible to accomplish the object fully and satisfactorily through the imperfect access thus afforded to the root of the tongue, $F$ resolved to divide the jaw at the symphisis, and then draw the two halves aside so as to get room for accurate dissection and ligature of the vessels.

G. S— aged forty-seven, a shoemaker, was admitted into the hospital on the 11th of November, 1857, suffering under extensive cancer of the tongue, which was diseased throughout its whole extent, except towards the root. He stated that only five months had elapsed since the commencement of his complaint, or, at all events, since his attention was first called to it. There was no glandular swelling, or any other sign of disease.

On the 9th of December, I made an incision throngh the lip, and extended it down towards the os hyoides, then sawed through the thick part of the symphisis, and completed its division by cutting pliers, next had the two halves held aside while I dissected backwards, so as to cut and tie the lingual arteries near the cornu of the os hyoides, and finally detached the tongue closely from the body of this bone. The edges of the wound were then brought together, and the patient walked stoutly to bed. Food was supplied by the injection of milk and beef-tea through a tube introduced into the oesophagus, and everything went on so favourably for several days that $I$ entertained no doubt as to the patient's recovery. But on the fourth day he began to complain of uneasiness in his chest, had a quick pulse, and became feeble. These unpleasant symptoms rapidly assumed a still more serious aspect, and terminated fatally on the seventh day. On dissection, the wound, larynx, and trachea were found in a satisfactory state; but the lungs were thickly interspersed with small indurations indicative of recent inflammatory action.

In considering this case, I felt at some loss to determine whether the fatal issue had necessarily resulted from the operation, or was owing to circumstances that admitted of prevention. The patient was ascertained to have been addicted to habits of 
intemperance. The wound had been healed throughout its whole extent, so as to leave no room for the escape of discharges from the fauces, and from an early period after the operation experiments had been tried on the power of deglutition with the effect of exciting a great deal of sputtering and cough. It seemed not improbable that, but for these unfavourable circum. stances, the operation might have proved successful, and therefore, although certainly having no great desire to repeat it, I did not feel entitled to decline doing so should a proper case ptesent itself.

A few weeks ago I received an application from the Hospital st Northampton to admit a patient, who appeared a very suitable subject for the purpose. He was fifty-eight years of age, a remarkably respectable, healthy-looking man, without the slightest sign of glandular disease. He had suffered for nearly six years from disease of the tongue, and in the early part of last spring had undergone an operation by ligature in the Northampton Hospital. In consequence of the disease returning, he afterwards went to London (Guy's Hospital), where no operation was performed, but some strong applications were employed. He then went home, with the tongue greatly swelled, and diseased throughout its whole extent, except towards the root, where the texture retained its ordinary characters, so far as could be ascertained by the finger.

On the 3lst of July, I performed the operation precisely as on the former occasion; but instead of closing the wound throughout its whole length, left about an inch of it open at the lower part, and inserted a piece of lint to prevent adhesion. I also directed that no food should be given except by injection through a tube. Again things went on favourably for a few days, and again I entertained sanguine expectations of success; but on the evening of the third day, symptoms of the same alarming character as in the first case showed themselves, so that next day I saw there was no hope, and felt prepared for the fatal result, which took place on the following day. On dissection, the air-passages were again found free from signs of disease until they reached the lungs, where there were extensive indications of recent inflammation.

In both of these cases it was manifest from inspection of the mass removed that no other operation could have accomplished complete extirpation of the tongue, and unless this were done, no better result could be anticipated than from the partial removal, which has always been found so useless and objectionable. On the other hand, I felt satisfied from the similarity of the symptoms and result, that the operation, if not certainly fatal, must be one of extreme danger; and as even in the event of success, the permanency of relief would still admit of question, I think there should be no hesitation in deciding against the repetition of this procedure. In promoting the progress of surgery, it is hardly of more consequence to determine what is expedient than to ascertain what is not expedient; and $I$ venture to hope, that the experience now related may not prove useless by saving others from the disappointment which I have myself experienced.

Edinburgh, August, 1858.

\section{ON THE}

\section{TREATMENT OF DYSENTERY BY THE ADMINISTRATION OF LARGE DOSES OF IPECACUANHA.}

\author{
BY E. S. DOCKER, EsQ. \\ BURGEON OF THE 2ND BATTALION OF TBE 7TH ROYAL FUSILIERS.
} (Concluded from page 115.)

I Now come to one of the worst cases that occurred in the 5th Fusiliers during the time $I$ was in medical charge. This case exhibits the specific action of large doses in dysentery in a striking manner. At that time I was not so fully conversant with this medicine, and as the man was extremely ill at the time of admission I deemed it advisable at first to employ calomel; and this medicine, which by many is looked upon as a specific in dysentery, had a fair trial-so fair, indeed, as to place the life of the patient in considerable jeopardy. At this juncture it will be observed by those practically conversant with dysentery that the man's symptoms were indicative of extremest danger. Fortunately, recourse was had to ipecacuan; and this medicine was given in full (drachm-and-a-half) doses three times. But I must not anticipate. As this case is so interesting, I make no apology for transcribing it nearly in ull :-

Private J. T_-, aged twenty-eight, admitted March 18 th, 1855; a slight, narrow-chested, delicate man. Has frequent purging of copious stools, consisting mostly of fluid-feculent matter, with some admixture of mucus and much blood. Says "he has no pain in the belly, no tenderness on pressure." (This was taken cum grano salis, for there was an evident disposition to make as light as possible of his complaint: he knew he had been guilty of disobedience of orders in not coming to hospital sooner. Closely questioned, he at last confessed that he had been ill for several days before reporting himself sick.) Admits having tenesmus. He was under treatment for acute dysentery in April, 1852. Ordered an emetic immediately, and every four hours a draught consisting of oil of turpentine, ten minims; acacia mucilage, half an ounce; tincture of opium, twenty minims; perpermint-water, one ounce. In the evening the report was: "Has passed since morning two scanty dysenteric stools." Ordered half an ounce of castor oil and twenty drops of laudanum.

March 19th.-Fight motions during the night, copious, feculent, and semi-fluid, with some froth tinged with blood on the surface; pulse 92, soft; tongue coated in the centre. To continue draughts of turpentine, \&c.-Evening: Bowels have acted three times since morning; stools scanty, and of a highly dysenteric appearance. Ordered ten grains of calomel and one of opium immediately; the same to be repeated at four o'clock in the morning.

20 th. - Has had during the night eight or nine motions, fluid, dark-coloured, feculent, with a little mucus, and more blood on the top; straining very severe, and there is much tenderness on pressure over the cæcum; pulse 132, soft and rather full ; tongue furred. Ordered-calomel, two grains and a half; tartar emetic, one-eighth of a grain; hydrochlorate of morphia, one-sixth of a grain, every four hours. - Evening: Bowels moved eleven times since morning; stools more dysenteric in appearance, with less of feculent matter. A sinapism was ordered to be applied immediately over the stomach ; internally, sixty minims of landanum, and half an hour after, a draught consisting of a drachm and a half of ipecacuan to an ounce and a half of water.-Ten P.M.: The report was that he retained the ipecacuan draught two or three minutes only; has been moved twice since six P.M.; stools very bad indeed, quite liquid, with hardly a trace of feculence, consisting chiefly of a little mucus and a very large proportion of fluid blood; he is excessively weak; pulse rapid and thready, intermittent; surface cold, and bathed in perspiration; tenesmus severe. The opiate dranght was now repeated, but this time with twenty minims only of laudanum; half an hour after, ninety grains of ipecacuan, as at six o'clock.

21st. - Has passed a tolerable night, and feels better, bowels not having been once moved since the administration of the last dose of ipecacuan, which he retained an hour and a half, then vomiting three times. He feels nausea at present. Is perfectly composed, and free from pain or irritability. Pulse 120, full and soft; tongue furred, but moist.-Evening: No action of the bowels since morning; the draught was retained three hours: he then vomited once. To have, at bed-time, a draught composed of liquor acetate of ammonia, half an ounce; liquor acetate of morphia, thirty minims; tincture of matico, and compound tincture of lavender, of each one drachm; peppermint water, one ounce.

22nd.-Marked improvement in every respect. After an interval of thirty-four hours his bowels have at last acted, during the night, once only; stool scanty, semi-consistent, feculent, and homogeneous, without a trace of blood or mucus. $\mathrm{He}$ is entirely free from pain or tenesmus, and perfectly com. fortable in every way. Draught last ordered to be continued every six hours.

23rd. - Improvement continues. No motion since last report. Pulse 100 , jerking; tongue coated. Ordered, camphor mixture, one ounce; liquor acetate of ammonia, half an ounce; disulphate of cinchona, two grains; tincture of lavender, one drachm : to be taken every four hours. Chicken broth; brandy, half a gill. 24th.-One scanty, consistent, entirely feculent stool; pulse 90 , soft; tongue cleaning. Ordered, infusion of gentian, two ounces; disulphate of cinchona, two grains: three times a day. Brandy, one gill.

25th. - Improvement maintained. To motion. Gentian draughts repeated.

$26 \mathrm{th}$.-Continues to get better; one natural evacuation. Tonic draughts continued. Broiled chicken.

27 th.--Same report. He is very weak. Draughts continued. Ordinary diet, and brandy. 